\title{
The Relationship between Learning Styles and Metacognitive Reading Strategy of EFL Learners
}

\author{
Zohreh Jafarpanah \\ M.A. student in TEFL, Department of ELT, College of Literature and Humanities, \\ Kermanshah Science and Research Branch, Islamic Azad University, Kermanshah, Iran \\ Department of English, College of Literature and Humanities, Kermanshah Branch, Islamic \\ Azad University, Kermanshah, Iran.
}

No. 98, Second avenue, Karmandan Street, Blvd. Tagh Bostan, Kermanshah, Iran Tel:09183576686Ｅ-mail: Zohreh9098@gmail.com

Majid Farahian (Corresponding author)

Department of ELT, College of Literature and Humanities, Kermanshah Science and Research Branch, Islamic Azad University, Kermanshah, Iran.

Department of English, College of Literature and Humanities, Kermanshah Branch, Islamic Azad University, Kermanshah, Iran.

E-mail: farahian@iauksh.ac.ir

Received: October 27, 2015 Accepted: January 18, 2016 Published: February 12, 2016 doi:10.5296/ URL: http://dx.doi.org/10.5296/

\begin{abstract}
Learning styles and strategies are among the important factors which affect the learners' performance in foreign language learning. The present study investigated the relationship between learning styles and metacognitive reading strategy of Iranian EFL (English as Foreign language) learners. It has also made an attempt to discover which learning style has the strongest correlation with metacognitive reading strategy. Accordingly, a total sample of 128 students who studied EFL at university was asked to answer a proficiency test. The purpose of administrating the proficiency test was to have a homogenized group of
\end{abstract}


intermediate EFL learners. As the next step, the participants were asked to answer two questionnaires which explored their metacognitive reading strategy and learning styles. The data analysis indicated that thirteen learning styles out of twenty-three ones have a significant, positive correlation with metacognitive strategy. Moreover, there was a significant correlation between visual, auditory, introvert, intuitive, concrete, closure-oriented, synthesizing, analytic, sharpener, deductive, field independent, metaphoric, and reflective styles with metacognitive reading strategy. In addition, among 23 learning styles, visual, closure- oriented and synthesizing styles had the strongest correlation with metacognitive strategy. The findings revealed that Iranian EFL learners with these three learning styles use more metacognitive reading strategy.

Keywords: Learning Styles, Metacognitive Reading Strategy, Foreign Language Reading

\section{Introduction}

It goes without saying that learning a foreign language (FL) can be studied from different perspectives such as biological, cognitive, social, psychological and communicative aspects. In each of these areas, there are large varieties of factors which may affect the process of foreign language learning. Learning styles and strategies are among these factors.

According to Oxford (1990), among all other factors, learning style and strategies have a crucial role in FL acquisition. Regardless of the method which the teachers use to instruct a FL, serious consideration should be taken to the fact that each individual has his/her way of learning. In other words, people learn in various ways, by seeing, hearing, analyzing, visualizing, thinking, memorizing, reasoning etc. Thus, each individual in the process of learning has his/her own unique characteristics known as learning styles. On the other hand, strategies are plans or techniques which are consciously used by learners to achieve a specific purpose or solve a problem or task. In other words, these are some techniques or devices used by the learners in order to acquire knowledge (Rubin, 1975).

In the case of the relationship between learning style and strategy, many researchers in their studies have reported that a learner's style preference generally has a wide influence on her strategy use (e.g. Carrell, 1988; Wen \& Johnson, 1997). According to Oxford and Nyikos (1989), language learners tend to use those strategies which reflect their learning styles. Brown (2007), in the same vein, points out that, learning strategies do not operate by themselves, but rather are directly linked to learners' innate learning style and other personality-related factors. Therefore, the ways in which learners process information affect strategies which they select. If the learning strategies do not match learners' learning styles, learners cannot have a good performance on language learning. In this regard, Pfister (cited in Sadeghi, 2012) conducted a research on the relationship between personality types and English reading comprehension among students in the United States. The result of his investigation revealed that students with extrovert and perceiving type have better performance in interpretative comprehension while students with sensing and feeling type are good at literal comprehension.

The relationship between learning styles and strategies in various EFL skills has been taken 
into consideration by many researchers. Reading as one of the important educational goals in FL teaching has been investigated in the present study. The idea that successful readers use more strategies in reading comprehension and poor readers are little aware of reading strategies (Chamot \& Kupper, 1989), leads the study to find the relationship between EFL learners' metacognitive reading strategies and their learning styles in order to raise EFL learners' awareness of the ways by which they can improve their metacognitive strategy in reading and overcome their weakness in using it. Moreover, research in this area has sufficed to explore only one or two learning style preference. Thus, the present study may shed more light on the relationship between various learning styles and metacognitive reading strategies.

\subsection{L2 Reading Strategy}

Many studies have been carried out to explore the relationship between styles, strategies, and different EFL skills. In this regard, one of the important skills which have been taken in to consideration by researchers is EFL reading. The beginning point in researching L2 reading strategy dates back to the late 1970s and early 1980s. Under the impact of cognitive psychology, the earliest research focused on the relationship between cognitive strategies and both successful and unsuccessful EFL readers. In fact, the role of using strategies in FL reading as a criterion for making distinction between good and poor readers has been the main focus of many empirical investigations. Honsenfeld (1977) asserts that good readers apply various strategies in reading such as neglecting unnecessary vocabularies, guessing meaning from context, reading in broad phrases and keeping on reading when decoding failed. Thus, there is a relationship between using strategy and proficiency in reading comprehension. Knowledge of strategies enables readers to have a better performance in FL reading while poor readers, who do not apply them, fail in comprehending the text. Anderson (1991) in his research emphasized that knowing how to use strategies in reading can distinguish a weak reader from a good one. Aebersold and Field (1997) define reading strategies as "the mental activities that the readers use in order to construct meaning from a text" (p. 14).

\subsection{Learning Style}

Learning styles can be recognized from the development of the term "individual differences". They can be interpreted as stable characteristics which affect the ways in which learners acquire (receive, retain, analysis, store) information. Since these enduring tendencies are different from individual to individual, each person has his/her own pattern of thinking and feeling. This definition is also true in the case of FL learning. Learning styles have been studied from a large numbers of perspectives. According to Reid (1995), learning styles "refer to an individual's natural, habitual and preferred way of absorbing, processing and retaining information and skills"(p.8).As such, It is evident that the learning styles are concerned with how to learn rather than what to learn. Individuals receive and process information by thinking, hearing, reflecting, acting, reasoning, analyzing, and visualizing. There is no doubt that learning styles affect the behavior of learners in the way they receive, retain, and interact with environment. Reid (1995) asserts that, being aware of learning styles is essential for both teachers and students. Learning styles may help learners recognize their 
strength and weakness in learning.

\subsection{Leaning strategy in FL learning}

Oxford (1975) points out learning strategies are "specific actions taken by learners to make learning easier, faster, more enjoyable, more self-directed, more effective and more transferable to new situation" (p. 8). According to oxford (1990), strategies are "specific actions, behavior, steps or techniques that students use -often consciously- to improve their progress in apprehending, internalizing, and using the second language" (p. 63). The term "consciousness" which is stated by Oxford in defining strategies, has been debated by many researchers. However, some emphasize that it is necessary for learners to acquire and apply strategies consciously. Cohen (1998) believes that when a learner uses a strategy habitually, and his/her conscious is not involved within the task, it became a process. In the same line, Pressley and Mac Cormick (cited in Hsiao \& Oxford, 2002) assert that "strategies must be controllable" (p. 28) because they are steps which are employed to achieve learners' goal. Cohen (1990) emphasizes on "being conscious" in describing strategies and explain strategy as " process which are consciously selected by learners and which may result in actions taken to enhance the learning or use of a second language through the storage, retention, recall and application of information about that language" (p. 4).

\subsection{Metacognitive Strategy}

Among the strategies which are used to improve reading comprehension, metacognitive awareness strategy is the first step to design a plan to improve reading skill of a SL (Carell, 1989). The importance of metacognitive strategy in FL learning has been emphasized by many researchers. It has been argued that "learners without metacognitive approaches have no direction or ability to monitor their progress, accomplishments, and future learning directions" (O`Malley et al., 1985, p. 36). O’Malley and Chamot (1990) define metacognitive strategy as strategy which students use to plan, monitor, and evaluate their learning goals and processes. Oxford (1990) explains that metacognitive strategy is an action which is more than a cognitive device and it can monitor learners' learning process.

Researching on teaching metacognitive strategies began to develop when reading specialist found out that cognitive strategies do not necessarily improve EFL reading and teaching them to learners cannot help learners to become more efficient readers. In fact, readers in dealing with a real text encounter different problems; and understanding when, how, and why using strategies is of great importance. Pressley and Afflerbach (1995), describe a good reader, from a metacognitive perspective, as a person who uses this strategy in text wherever necessary and tries to modify the process of reading.

Despite wealth of research on the role of metacognitive strategies in SL/FL reading, the unanswered question is whether there is any significant relationship between learning styles and metacognitive reading strategy. Accordingly, the present study focused on answering the following questions: 1. Is there any significant relationship between Iranian EFL learners' learning style and their metacognitive reading strategies? 2. Among learning styles, which one has the strongest correlation with metacognitive reading strategies? 


\section{Methodology}

\subsection{Participants}

The number of participants in this study was 128 undergraduate students who studied English as a FL language at university. The average participant's age was 18 to 33. They were selected from three different universities located in Kermanshah, a city in west of Iran. A proficiency (Nelson) test was administrated to participants to homogenize them in terms of intermediate reading comprehension. Then, 91 students who got 30 (pass mark, as reported in Nelson) out of 50, were selected. They include 23 males and 68 females.

\subsection{Instruments}

In the present study two questionnaires and one proficiency test were used. Nelson Test by Fowler and Coe (1976) was used to determine the language proficiency of participants in reading comprehension. Moreover, in order to assess the participants' learning style, the leaning style survey by Cohen, Oxford and Chi (2001) was employed which includes 11 sections, 23 subscales and 110 items. Another instrument was Metacognitive Awareness of Reading Strategies Inventory (MARSI) developed by Mokhtari and Reichard (2002) which was used to measure the metacognitive strategy in SL reading.

\subsection{Procedure}

First the participants were required to respond to the Nelson English Language. As a result, about 91 students out of 128 ones could get the pass mark. After administering the Nelson test, the participants were asked to answer two inventories including Learning Style Survey and MARSI. Since the total number of items in both inventories was 140 and the participants had difficulty answering them thoroughly at that time, they were allowed to take them home and complete them in a week. In order to identify the relationship between leaning styles and metacognitive strategy, Pearson correlation and Regression Model (SPSS) were conducted.

\section{Result}

The findings show that there is a significant relationship between learning styles and metacognitive strategy since P-value is 0.00 .

Table 1. The Summery of Correlation between Learning Styles and Meta Strategy

\begin{tabular}{cccccc}
\hline Model & Sum of Scores & Df & Mean & F & Sig. \\
\hline Regression & 11782.89 & 4 & 2945.72 & 23.77 & 0.00 \\
Residual & 10655.67 & 86 & 123.90 & & \\
Total & 22438.57 & 90 & & & \\
\hline
\end{tabular}

Correlation is significant at $\mathrm{p}<.05$.

Table 1 shows the P-value of the relationship between learning styles and metacognitive strategy. 
Table 2. The Correlation between Learning Styles and Metacognition Strategy

\begin{tabular}{|c|c|c|c|}
\hline \multirow{3}{*}{$\begin{array}{l}\text { Learning Styles } \\
\text { Visual }\end{array}$} & \multicolumn{3}{|c|}{ Meta. Strategy } \\
\hline & \multicolumn{2}{|c|}{ Pearson Correlation } & \multirow{2}{*}{$\begin{array}{l}\text { Sig. (2 tailed) } \\
0.00\end{array}$} \\
\hline & 0.50 & $*$ & \\
\hline Auditory & 0.36 & $*$ & 0.00 \\
\hline Tactile & -0.00 & & 0.97 \\
\hline Extrovert & -0.07 & & 0.48 \\
\hline Introvert & 0.20 & * & 0.05 \\
\hline Intuitive & 0.45 & $*$ & 0.00 \\
\hline Concrete & 0.34 & * & 0.00 \\
\hline Closure & 0.50 & $*$ & 0.00 \\
\hline Open & 0.01 & & 0.87 \\
\hline Global & 0.14 & & 0.15 \\
\hline Particular & 0.16 & & 0.12 \\
\hline Synthesizing & 0.47 & $*$ & 0.00 \\
\hline Analytic & 0.29 & $*$ & 0.00 \\
\hline Sharpener & 0.41 & $*$ & 0.00 \\
\hline Leveler & 0.20 & & 0.05 \\
\hline Deductive & 0.42 & $*$ & 0.00 \\
\hline Inductive & 0.12 & & 0.23 \\
\hline F- independent & 0.43 & $*$ & 0.00 \\
\hline F-dependent & -0.05 & & 0.59 \\
\hline Impulsive & -0.04 & & 0.70 \\
\hline Reflective & 0.37 & $*$ & 0.00 \\
\hline Metaphoric & 0.39 & $*$ & 0.00 \\
\hline Literal & -0.04 & & 0.68 \\
\hline
\end{tabular}

*Correlation is significant at $\mathrm{p}<.05$.

The Pearson correlation was used to find out whether there was a significant, meaningful relationship between each learning style and metacognitive strategy. The result indicated that among 23 learning styles, 13 learning styles had a meaningful relationship with metacognitive strategy. The results are shown in Table 3.2 and the significance of correlation is described at $\mathrm{p}<0.05$ which is shown with a star. It indicates that learning styles including visual, auditory, introvert, intuitive, concrete, closure, synthesizing, analytic, sharpener, deductive, f-independent, reflective and metaphoric have meaningful relationship with metacognitive strategy. It was also revealed that among 23 learning styles, visual, closure and synthesizing styles have the strongest correlation with metacognitive strategy which means the individual with these learning styles use more metacognitive strategy in FL reading. In addition, learning styles including open, global, particular, leveler and inductive have no relationship with metacognitive strategy, but tactile, extrovert, f-dependent, impulsive and literal have negative relationship with metacognitive strategy. 


\section{Discussion}

As the findings revealed, there was a significant positive relationship between thirteen learning styles (visual, auditory, introvert, intuitive, concrete, closure, synthesizing, analytic, sharpener, deductive, f-independent, and reflective) and using metacognitive strategy in FL reading. Among these learning styles, visual, closure and synthesizing have the strongest correlation with metacognitive strategy. In other words, learners with these learning styles use more metacognitive strategy in FL reading.

Synthesizing learners, who have the characteristics such as summarizing materials, enjoying guessing meaning, predicting outcomes and noticing similarities, are found to use metacognitive strategy in their learning process in a study conducted by Shi (2011). Moreover, visual learners in other studies such as Shannon's (2008) preferred to use the items in metacognitive strategy including self-assessment, self-questioning and evaluation. But, he also indicated that tactile learners use selective strategy which is one of the items in metacognitive strategy, this rejects the finding of present study which indicates there is a negative relationship between tactile and metacognitive strategy. Base on the type of learning styles, each learner tends to use specific strategies more than the other strategies in FL learning. This means that we can predict type of learning strategies used by learners through their learning styles. Such a predictable relationship have been stated by many researchers such as Cohen and Weaver (2005), Ehman and Oxford (1989). Thus, it can be concluded that learning styles have considerable influence on strategy choice.

The link between learning styles and using metacognitive strategy is an important issue which should be taken in to account. It appears that recommending a particular strategy such as metacognitive, by teachers is not sufficient, more consideration should be taken to learning styles and personality characteristics in strategy choice. As Oxford (1990) emphasizes, learners tend to select those strategies which reflect their learning styles. Such a match makes learners to have an active, purposeful and conscious learning. In contrast, if there is no match between styles and strategies, students may feel anxious, less confidence and have poor performance in the process of learning.

\section{Conclusion}

The findings of the study indicated that there is a significant relationship between learning styles with metacognitive strategy and also there is a significant relationship between 13 out of 23 learning styles with metacognitive reading strategy. In addition, it was found that visual, closure-oriented and synthesizing styles have the strongest correlation with metacognitive reading strategy.

The findings of present study are in line with Sadeghi, Kasim, Tan and Abdullah (2012). As they reported in their study, there was a relationship between learning styles and reading comprehension. They assert that learners' learning styles affect their performance in FL reading. The findings are also in tandem with that of Pfister (cited in Sadeghi, 2012) who found a significant relationship between personality type and EFL reading comprehension.

Another study conducted by Khodae, Hashemnezhan and Javadi (2013) indicated that there is 
a positive correlation between Iranian EFL learning styles and using learning strategies.

The result of the study can also shed lights on the relationship between learning styles and metacognitive reading strategy among EFL learners. There is no doubt that each learner has a particular learning styles preference. In addition, having known which learning style uses more or less metacognitive strategy, the learners can recognize their strength or weakness in strategy use in reading comprehension. The more learners know about their strength and weakness, the more effectively they can orient their FL learning.

The findings may also give more insight regarding the importance of some of learning styles in FL reading. Teachers should be aware of EFL students' learning styles. Having being aware of learner's learning styles; teachers can make balance in their method of teaching and instructions and also adapt their teaching styles. It also gives them the awareness that they should employ a large number of activities which can provide learners' needs base on their personal characteristics.

Furthermore, the match between learning styles and metacognitive strategy may give hints to material developers and curriculum designer to prepare materials which provide the needs of the learners regarding to the interconnection between learning styles and strategies of EFL learners. However, it is worth mentioning that the relationship found in this study is only one part of the issue. As it was stated earlier, other factors such as age, gender, level of proficiency, culture and motivation may affect strategies use in FL. Therefore, it is essential for teachers and instructors to be aware of all factors.

Finally, since using metacognitive strategy is a criterion to identify a good reader from a poor one (Pressley \&Afflerbach, 1995) and because Iranian EFL learners use metacognitive strategy more than the other strategies (Nikoopour \& Farsani, 2010); the finding may suggest that teachers need to incorporate this strategy in their method of teaching.

\section{References}

Aebersold, J. A., \& Field, M. L. (1997). From reader to reading teacher: Issues and Strategies for second language classrooms. Cambridge: Cambridge University Press.

Anderson, N. J. (1991). Individual differences in strategy use in second language reading and testing. Modern Language Journal, $460-472$. http://dx.doi.org/10.1111/j.1540-4781.1991.tb05384.x

Brown, D. H. (2007). Principles of language learning and teaching. Pearson: Longman.

Carrell, P., Devine, J., \& Eskey, D. (1988). Interactive approaches to second language reading. New York: Cambridge University Press. http://dx.doi.org/10.1017/CBO9781139524513

Carrell, P. L. (1989).Metacognitive awareness and second language reading. The Modern Language Journal, 73, 121-134. http://dx.doi.org/10.1111/j.1540-4781.1989.tb02534.x

Carrell, P. L. (1998). Can reading strategies be successfully taught? The Language Teacher.

Chamot, A. U., \&Kupper, L. (1989).Learning strategies in foreign language instruction. 
http://dx.doi.org/10.1111/j.1944-9720.1989.tb03138.x

O'Malley, J. M. (1985). Learning strategies used by beginning and intermediate ESL students. Language Learning, 35(1), 21-44. http://dx.doi.org/10.1111/j.1467-1770.1985.tb01013.x

Oxford, R. L., \& Burry Stock, J. A. (1995). Assessing the use of language learning strategies worldwide with the ESL/EFL version of the Strategy Inventory for Language Learning. System, 23(2), 1-23. http://dx.doi.org/10.1016/0346-251X(94)00047-A

Oxford, R. L. (1990). Language learning strategies: What every teacher should know. New York: Newbury House Publishers.

Oxford, R. L. (2003). Language learning styles and strategies: An overview. Learning Styles.

Oxford, R., \& Nyikos, M. (1989). Variables affecting choice of language learning strategies by university students. Modern Language Journal, 73, 291-300. http://dx.doi.org/10.1111/j.1540-4781.1989.tb06367.x

Pressley, M., \&Afflerbach, P. (1995). Verbal protocols of reading: The nature of constructively responsive reading. Hillsdale, NJ: Lawrence Erlbaum.

Reid, J. M. (1995). Learning styles in the ESL/EFL classroom. U.S.A: Heinle \& Heinl Publishers.

Rubin, J. (1975). What the "good language learner" can teach us. TESOL Quarterly, 9, 41-51.http://dx.doi.org/10.2307/3586011

Sadeghi, N., Kasim, Z. M., Tan, H. B., \& Abdullah, S. A. (2010). Learning styles, personality types and reading comprehension performance. English Language Teaching, 5(4), 116-123.

Shannon, V. S. (2008). Using Metacognitive strategies and learning styles to create self-directed learners. Institute for Learning Styles Journal, 1, 14-28.

Shi, C. (2011). A study of the relationship between cognitive styles and learning strategies. Higher Education Studies, 1(1), 20-25. http://dx.doi.org/10.5539/hes.v1n1p20

Wen, Q., \& Johnson, R .K. (1997). L2 learner variables and English achievement: A study of tertiary-level English majors in China. Applied Linguistics, 18, 27-48. http://dx.doi.org/10.1093/applin/18.1.27

\section{Copyright Disclaimer}

Copyright reserved by the authors.

This article is an open-access article distributed under the terms and conditions of the Creative Commons Attribution license (http://creativecommons.org/licenses/by/3.0/). 